\title{
Increasing Channel Profit in the Sale of Durable Goods
}

\author{
Nian Guo and Zhongkai Xiong \\ School of Economics and Business Administration, Chongqing University, Chongqing, China \\ Correspondence should be addressed to Zhongkai Xiong; xiongzhongkai@cqu.edu.cn \\ Received 22 April 2016; Revised 3 November 2016; Accepted 6 November 2016 \\ Academic Editor: Laura Gardini
}

Copyright (C) 2016 N. Guo and Z. Xiong. This is an open access article distributed under the Creative Commons Attribution License, which permits unrestricted use, distribution, and reproduction in any medium, provided the original work is properly cited.

\begin{abstract}
Both time inconsistency and double marginalization are important issues in the sale of durable goods. In particular, when a durable goods manufacturer sells her product through a conventional retail store, the intrinsic double marginalization would alleviate time inconsistency to some extent. However, current research pays no attention on the interaction between both issues under multipleretailer and manufacturer encroachment scenarios. To fill this gap, in this paper, we study these two channel structures in the sale of durable goods. Our analysis reveals that channel profit in the multiple-retailer structure is always greater than that under integration. On the other hand, the manufacturer encroachment structure can eliminate both bad effects without commitment under some circumstances and the whole channel is well coordinated.
\end{abstract}

\section{Introduction}

Online channels have gained more and more popularity since they provide a quick and convenient way to sell products to customers. Many manufacturers who have already owned conventional retail stores deem the Internet as a promising marketing channel to increase their profits. Gateway, a personal computer firm, has even closed all of its self-owned retail stores and sells only through independent retailers and direct Internet channel [1]. In spite of the Internet frenzy, some firms began to reexamine the role of conventional retail channels. It is reported that Dell has added self-owned retailers to its existing online channel since the second half of 2006 [2]. Using retailers to market products would incur double marginalization while the direct Internet channel would not. On the other hand, retailers often have an advantage over the direct channel in the sale process due to various reasons [3]. Hence, the battle between "bricks" and "clicks" remains to be an important issue in the marketing literature.

Despite the popularity of online shopping, its impact on the issue of product durability has received little attention in the dual-channel and durable goods literatures. Unlike nondurable goods firms, durable goods manufacturers face the famous time inconsistency problem if they intend to sell their products. If such a manufacturer could not make a commitment not to flood the market in future periods, rational customers will postpone their purchase and the manufacturer would lose her monopolistic power. This idiosyncrasy adds more complexity to the "bricks" and "clicks" competition when the manufacturer has an option to open a direct channel. In the durable goods literature, it has been widely recognized that adding an intermediary to the marketing channel may be beneficial to the entire supply chain in the sale of durable goods $[4,5]$. This is because double marginalization can alleviate the time inconsistency problem by signaling that market prices for the product will be kept high in later periods via naturally restricted supply, especially when a long horizon is considered [5]. In the meanwhile, it is also well known that the time inconsistency can mitigate the double marginalization such that if a durable monopolist has to rely on an intermediary, then it prefers to go through a selling one rather than a leasing one [6]. Thus, there is actually a cannibalization relation between the two bad effects. However, it is still not clear how the Internet channel entry will affect the cannibalization between the two effects. On the other hand, the effect of the competition between conventional stores on the durable goods supply chain also lacks scrutiny. Hence, in this paper, we address those issues and explore the interplay among all these factors.

To elaborate, we consider two channel structures: multiple-retailer and manufacturer encroachment. In the 
multiple-retailer structure, the manufacturer sells to identical independent retailers who in turn sell to customers. If the manufacturer adds only one retailer, Arya and Mittendorf [5] prove the channel value under one-retailer decentralization would exceed that under integration when the product lasts three periods. Now with the competition between retailers, double marginalization is alleviated and time consistency is aggravated in the multiple-retailer structure. Through marinating a reasonable number of retailers, the benefit gained from relative more production in early periods outweighs the cost of commitment in the future such that the whole channel value can be greater than that under integration in even two periods. But this structure also has its limitation. As the product life cycle increases further, it will finally reduce to the one-retailer decentralization.

In the manufacturer encroachment structure, the manufacturer sells through an independent retailer and has an option to open a direct channel. We demonstrate if the unit cost of operating the direct channel satisfies a certain value, the manufacturer can credibly refrain from entering online in all periods and force the retailer to order more products in early periods. Thus, both double marginalization and time consistency are eliminated and the channel profit can reach its maximal value, or in other words the channel is well coordinated. We also identify an interesting phenomenon that the usual underproduction problem may turn into an overproduction one and the customers' rational expectation could be reversed. Our results suggest that Internet channel entry may be a promising way to increase the profit of a durable goods channel. But the direct channel is not a panacea; the benefit it brings is at the mercy of its unit operating cost.

The rest of the paper is organized as follows. In Section 2, we review the most relevant literature to our paper. Section 3 describes the model assumptions and Section 4 discusses two important benchmarks that will be used as comparison with the multiple-retailer and manufacturer encroachment structures. In Sections 5 and 6, we elaborate on the two structures, respectively, and we conclude in Section 7.

\section{Literature Review}

Our paper is closely related to two distinct streams of the marketing literature. One is the research which discusses the role of intermediaries in the marketing of durable goods. The other is about an upstream manufacturer's dual-channel strategies and the consequent channels conflict with conventional retailers. We will discuss them in detail below.

Within the durable goods domain, time inconsistency is a central issue. Beginning with Coase [7], it has been fundamental in the study of marketing durable goods and several solutions have been proposed to mitigate it. The most famous one is by leasing. Although leasing evades the time inconsistency problem entirely, it has several deficiencies. First of all, antitrust policy requires manufacturers to sell rather than lease their products. Secondly, leasing may cause potential customer abuse of the product as pointed out by [8]. Thirdly, leasing may involve various costs, such as remarketing costs [9] or the cost of writing legal contracts with individual customers [4]. Finally, sale can enable a manufacturer to capture part of the market while leasing may result in loss of future market share to a rival [10].

Another promising direction is adding intermediaries to the distribution channel. Purohit [6] demonstrates that a manufacturer who uses an intermediary can reap more profits from sale than lease. Since using intermediaries will unavoidably induce a double marginalization problem, the finding of Purohit [6] implies that time inconsistency has an adverse effect on double marginalization. In the meanwhile, through extending a model of Desai et al. [4] which show time inconsistency could be eliminated if a manufacturer could commit to wholesale prices, Arya and Mittendorf [5] prove that double marginalization could also mitigate time inconsistency. Accordingly, Bhaskaran and Gilbert [11] construct a model to study the trade-off between the two effects by allowing all the members of the supply chain to choose to sell or lease. They find that when the level of competition among dealers is high, both the manufacturer and her dealers will adopt lease rather than sale. Our work distinguishes from them by considering the manufacturer's possible Internet channel entry decision. Since the decision will affect both bad effects, no matter positively or negatively, it will definitely affect the channel profit. We want to know whether the channel profit can be increased or even reach its maximal value.

With respect to the dual-channel literature, papers there mainly discuss issues like whether a manufacturer should open an online store and what consequences the manufacturer's encroachment will bring to the conventional retail store. Cai [12] studies two single-channel and two dualchannel supply chains. He systematically compares the four channel structures and investigates their impacts on all members of the supply chain. Liu et al. [13] show that when price is required to be uniform across channels, an incumbent conventional retailer can deter a pure e-tailer's online entry simply by refraining from entering online. Arya et al. [3] demonstrate that, contrary to the common wisdom, the encroachment of an upstream manufacturer who depends on a retailer to sell their products is not always detrimental to the retailer and the entire supply chain. In another paper, Arya et al. [14] extend their model and point out that such an upstream manufacturer can benefit from decentralized control by establishing a self-owned retailer and compete with the incumbent retailer in the retail realm. Yoo and Lee [1] investigate various mixed channel structures composed of a monopoly manufacturer and online and offline outlets to study the different dual-channel strategies among firms. They find that the impact of Internet channel entry varies across channel structures and they also propose a framework to explain the reasons. Although most of the research on dual channel ignores the product durability, there is a notable exception. Xiong et al. [15] address a durable goods manufacturer's dual-channel strategies. By considering a model in which the manufacturer sells through an e-channel and an independent dealer who adopts a mix of selling and leasing strategy, they mainly focus on under what conditions the manufacturer should open a direct channel and how would that affect the retailer's profit. 
Our work is distinct from them and contributes to the literature in two ways. First, we have found two channel structures that can increase the profit of the whole channel under integration and one-retailer decentralization. Second, we study the impacts of Internet channel entry and competition between retail stores on double marginalization and time inconsistency, which is absent in their papers.

\section{Model Setup}

In the manufacturer encroachment structure, a manufacturer can sell its products through two channels: an independent retailer and a self-owned e-channel. The manufacturer first announces the wholesale price to the retailer who then determines the optimal units of procurement. Finally, the manufacturer chooses how many units to sell through the echannel. The reason for choosing sequential encroachment (in which the manufacturer's retail output decision is after that of the retailer) instead of simultaneous encroachment (in which the manufacturer and the retailer choose their retail outputs simultaneously) is that all members are better off under sequential encroachment than under simultaneous encroachment [3]. Because the retailer often has an advantage over the e-channel in the sale process, we assume the unit cost of operating an e-channel is $c \in[0, \alpha]$, while all other costs related to the manufacturer and the retailer are normalized to zero. This assumption captures the elaborate balance between the e-channel and the conventional retail store. If $c$ is set to zero, the intrinsic inefficiency of the conventional retail channel will force the retailer to quit from the market and the model is reduced to an integrated one where the manufacturer sells only through the e-channel.

In the multiple-retailer structure, a manufacturer sells to identical independent retailers who then simultaneously decide their order quantities and sell to consumers. First we only consider two retailers and later we will investigate the optimal number of them in both two and three periods. The identicalness of the retailers means they are perfectly substituted and the number of retailers can be used to depict the degree of competition among them. We assume the manufacturer does not exert price discrimination and offers the same wholesale prices to both retailers as the Robinson Patman Act requires. Note here that we assume the manufacturer only sells to the two retailers instead of leasing. In selling, double marginalization and time inconsistency would both exist in the channel, while in leasing the channel would suffer only double marginalization. Because our interest is in understanding the impact the multiple-retailer structure will bring to the two effects in the same time, we explicitly restrict the manufacturer's flexibility and let the two effects coexist in the channel. Later, we will show this assumption is robust. Therefore, without loss of generality, the restriction simplifies our presentation and enables us to focus on the effects of the competition among the retailers.

For simplicity, we follow the traditional assumption in $[5,11,16]$ that the durable goods do not depreciate. We also consider both two-period and three-period life cycles and assume there is no discount between the periods as in [5] so that our results can be compared with theirs.
A perfect secondhand market is assumed to exist where there are no transaction costs for consumers to buy and sell a durable good. Hence, customers who buy the goods in period $n$ can sell them freely in period $n+1$. As is standard, the leasing price in period $n$ is $p_{l}^{n}=\alpha-\beta Q_{n}$, where $Q_{n}$ is the total quantity of the durable good available in period $n$. Let $q_{r i}^{n}$ and $q_{m}^{n}$ be the quantities chosen by Retailer $i$ and the manufacturer in Period $n$, respectively. Then, $Q_{n}$ becomes $\sum_{n}\left(q_{r}^{n}+q_{m}^{n}\right)$ in the manufacturer encroachment case and $\sum_{n}\left(q_{r 1}^{n}+q_{r 2}^{n}\right)$ in the multiple-retailer case, because in the last period sale equals lease. Therefore, in the two-period setting, Period 2 sale price is $p_{s}^{2}=p_{l}^{2}$. Period 1 sale price represents the present value of both periods' benefits, so it is $p_{s}^{1}=p_{l}^{1}+p_{l}^{2}$.

\section{Two Benchmarks}

The integrated and one-retailer decentralized channels are two benchmarks that we will use as a comparison with the manufacturer encroachment and multiple-retailer structures. We briefly summarize the results below.

In the integrated channel, a manufacturer sells directly to customers. Her Period 1 and Period 2 profits are $V_{m}^{1}=[2 \alpha-$ $\left.\beta\left(2 q_{m}^{1}+q_{m}^{2}\right)\right] q_{m}^{1}+\left[\alpha-\beta\left(q_{m}^{1}+q_{m}^{2}\right)\right] q_{m}^{2}$ and $V_{m}^{2}=\left[\alpha-\beta\left(q_{m}^{1}+\right.\right.$ $\left.\left.q_{m}^{2}\right)\right] q_{m}^{2}$. Backward induction yields the optimal selling prices, production levels, and the channel value as follows:

$$
\begin{aligned}
& p_{s}^{1 *}=\frac{9 \alpha}{10} \\
& p_{s}^{2 *}=\frac{3 \alpha}{10} ; \\
& q_{m}^{1 *}=\frac{2 \alpha}{5 \beta} ; \\
& q_{m}^{2 *}=\frac{3 \alpha}{10 \beta} \\
& V^{*}=\frac{9 \alpha^{2}}{20 \beta} .
\end{aligned}
$$

In the one-retailer decentralized channel, the manufacturer first sells to a retailer who in turn sells to customers. The manufacturer's Periods 1 and 2 profits then become $V_{m}^{1}=$ $w_{m}^{1} q_{r}^{1}+w_{m}^{2} q_{r}^{2}$ and $V_{m}^{2}=w_{m}^{2} q_{r}^{2}$, where $w_{m}^{n}$ is Period $n$ wholesale price. The retailer's Periods 1 and 2 profits are $V_{r}^{1}=[2 \alpha-$ $\left.\beta\left(2 q_{r}^{1}+q_{r}^{2}\right)-w_{m}^{1}\right] q_{r}^{1}+\left[\alpha-\beta\left(q_{r}^{1}+q_{r}^{2}\right)-w_{m}^{2}\right] q_{r}^{2}$ and $V_{r}^{2}=$ $\left[\alpha-\beta\left(q_{r}^{1}+q_{r}^{2}\right)-w_{m}^{2}\right] q_{r}^{2}$. Again, backward induction yields the equilibrium wholesale prices, production levels, and channel value as follows:

$$
\begin{aligned}
& w_{m}^{1 *}=\frac{379 \alpha}{416} \\
& w_{m}^{2 *}=\frac{41 \alpha}{104} \\
& q_{r}^{1 *}=\frac{11 \alpha}{52 \beta}
\end{aligned}
$$




$$
\begin{aligned}
q_{r}^{2 *} & =\frac{41 \alpha}{208 \beta} \\
V^{*} & =\frac{17671 \alpha^{2}}{43264 \beta} .
\end{aligned}
$$

It is obvious that channel profit under one-retailer decentralization is less than that under centralization. In a durable goods setting, a one-retailer decentralized channel suffers both double marginalization and time inconsistency while an integrated channel suffers only the later problem. It can be testified that the overall production levels in the one-retailer decentralization are less than those under centralization in both periods. This underproduction results in double marginalization but is a boon to time inconsistency by allowing the channel to commit being unable to lower price freely. Although the two bad effects would cannibalize with each other, the cost of underproduction proves to be large enough to outweigh the benefit of commitment in a twoperiod setting, where the channel's commitment problem is not so severe. As the product life cycle increases, the commitment problem begins to outweigh double marginalization and in just a three-period setting the channel value under one-retailer decentralization would exceed that under integration. But what changes will more complicated supply chain structures bring? We next analyze two of them and explore their impacts on the sale of durable goods.

\section{Multiple Retailer}

A common way of alleviating the double marginalization is to add more intermediaries. This is intuitive because the existence of other retailers can force the incumbent retailer to reduce retail price, which would result in higher demand. In a two-period durable goods setting, this means the underproduction problem in Period 1 can be mitigated while the commitment problem in Period 2 is more severe. As we have pointed out, the underproduction problem is a major factor when the product lasts for only two periods. Then, can the channel value under the multiple-retailer case exceed that under integration in a short product life cycle?

We first investigate the case of the manufacturer selling through two identical retailers. Given $q_{r 1}^{1}, q_{r 2}^{1}$, and the second-period wholesale price $w_{m}^{2}$, the two retailers simultaneously choose their Period 2 order quantities to maximize their Period 2 profits. Retailer 1's Period 2 problem is

$$
\max _{q_{r 1}^{2}} \quad V_{r 1}^{2}=\left[\alpha-\beta\left(q_{r 1}^{1}+q_{r 2}^{1}+q_{r 1}^{2}+q_{r 2}^{2}\right)-w_{m}^{2}\right] q_{r 1}^{2}
$$

First-order condition yields Retailer 1's optimal response:

$$
q_{r 1}^{2 *}=\frac{\alpha-\beta\left(q_{r 1}^{1}+q_{r 2}^{1}+q_{r 2}^{2}\right)-w_{m}^{2}}{2 \beta} .
$$

Because of the identicalness of the two retailers, we can take advantage of symmetry and write out Retailer 2's optimal response directly:

$$
q_{r 2}^{2 *}=\frac{\alpha-\beta\left(q_{r 1}^{1}+q_{r 2}^{1}+q_{r 1}^{2}\right)-w_{m}^{2}}{2 \beta} .
$$

Solving (4) and (5) simultaneously, we obtain

$$
q_{r 1}^{2 *}=q_{r 2}^{2 *}=\frac{\alpha-\beta\left(q_{r 1}^{1}+q_{r 2}^{1}\right)-w_{m}^{2}}{3 \beta} .
$$

Anticipating the two retailers' responses, the manufacturer chooses the second-period wholesale price $w_{m}^{2}$ to maximize her Period 2 profit. The manufacturer's Period 2 problem is

$$
\max _{w_{m}^{2}} \quad V_{m}^{2}=w_{m}^{2}\left(q_{r 1}^{2 *}+q_{r 2}^{2 *}\right)
$$

Plugging (6) into (7) and taking first-order condition yield Period 2 wholesale price:

$$
w_{m}^{2 *}=\frac{\alpha-\beta\left(q_{r 1}^{1}+q_{r 2}^{1}\right)}{2} .
$$

Back to Period 1, the three players make their decisions foreseeing the order quantities and wholesale prices in Period 2. Specifically, the two retailers again simultaneously choose their order quantities to maximize their Period 1 profits. Retailer 1's Period 1 problem is

$$
\begin{aligned}
\max _{q_{r 1}^{1}} & V_{r 1}^{1} \\
= & {\left[2 \alpha-\beta\left(2 q_{r 1}^{1}+2 q_{r 2}^{1}+q_{r 1}^{2 *}+q_{r 2}^{2 *}\right)-w_{m}^{1}\right] q_{r 1}^{1} } \\
& +V_{r 1}^{2 *} .
\end{aligned}
$$

Taking Retailer 1's first-order condition yields her optimal response:

$$
q_{r 1}^{1 *}=\frac{29\left(\alpha-\beta q_{r 2}^{1}\right)-18 w_{m}^{1}}{59 \beta} .
$$

Again, taking advantage of symmetry, we obtain

$$
q_{r 1}^{1 *}=q_{r 2}^{1 *}=\frac{29 \alpha-18 w_{m}^{1}}{88 \beta} .
$$

Recognizing the two retailers' optimal response, the manufacturer chooses the first-period wholesale price $w_{m}^{1}$ to maximize her Period 1 profit. The manufacturer's Period 1 problem is

$$
\max _{w_{m}^{1}} V_{m}^{1}=w_{m}^{1}\left(q_{r 1}^{1 *}+q_{r 2}^{1 *}\right)+V_{m}^{2 *}
$$


Plugging (11) into (12) and taking first-order condition yield Period 1 wholesale price. The equilibrium wholesale prices, order quantities, and channel value are

$$
\begin{aligned}
& w_{m}^{1 *}=\frac{683 \alpha}{738} \\
& w_{m}^{2 *}=\frac{59 \alpha}{164} ; \\
& q_{r 1}^{1 *}=q_{r 2}^{1 *}=\frac{23 \alpha}{164 \beta} ; \\
& q_{r 1}^{2 *}=q_{r 2}^{2 *}=\frac{59 \alpha}{492 \beta} ; \\
& V^{*}=\frac{27317 \alpha^{2}}{60516 \beta} .
\end{aligned}
$$

Comparing the channel value with that under integration leads to the following proposition.

Proposition 1. If a durable goods manufacturer sells through two identical retailers in two periods, the channel value is always greater than that under integration.

Proposition 1 is amazing because it indicates that the competition from adding another retailer is sufficient to make the channel value exceeds that under integration in two periods. Arya and Mittendorf [5] also find that under some circumstances the channel discord brought about by an intermediary can make a decentralized channel more appealing than an integrated one. But in their model, to achieve that goal, a longer product life cycle has to be investigated (at least three periods), while in our model, we demonstrate this can be achieved in just two periods.

We now examine the reason that underlies this phenomenon. In Period 1, the overall production level is $q_{r 1}^{1 *}+$ $q_{r 2}^{1 *} \approx 0.28 \alpha / \beta$ which is greater than $0.21 \alpha / \beta$, the production level when the manufacturer sells through only one retailer. That means the underproduction problem in the first period of one-retailer decentralization is alleviated to some extent. This is consistent with the standard view that the competition between downstream retailers can mitigate double marginalization. In the meanwhile, Period 2 overall production level is $q_{r 1}^{2 *}+q_{r 2}^{2 *} \approx 0.24 \alpha / \beta$, which is still greater than that under one-retailer decentralization, $0.20 \alpha / \beta$. Thus, adding another intermediary aggravates the commitment problem in the second period. But now, contrary to the one-retailer decentralization, the benefit of relative more production gained from Period 1 outweighs the cost of commitment in Period 2. It is this reversion of situation that makes the channel value exceeds that under integration when the product lasts for only two periods.

Since adding more retailers is a promising way to increase the channel value, one may want to make the best of the downstream competition and add retailers as many as possible. However, it turns out not to be a good idea. Then, how many intermediaries should be added? The following proposition answers that question.
Proposition 2. If the product lasts for two periods, adding four identical retailers would make the channel value the greatest when the manufacturer depends only on retailers to sell the durable goods.

Proof. See Appendix B.

Let us first discuss the robustness of the result. Recall that we have explicitly restricted that the manufacturer only sells. This restriction seems reasonable now as Bhaskaran and Gilbert [11] point out that when the number of intermediaries is not greater than 4 and uniform wholesale pricing is adopted, selling is more attractive than leasing for the manufacturer. In other words, the setting we assume is actually the equilibrium outcome when more flexibility is granted to the manufacturer and Proposition 2 is still true then.

Proposition 2 implies a durable goods channel can be further better off by maintaining an elaborate balance between double marginalization and time inconsistency. Specifically, the multiple-retailer structure mitigates the underproduction problem and aggravates the commitment problem than that under one-retailer decentralization through adjusting the number of retailers. When a channel's commitment problem is not so severe, like in only two periods, the multiple-retailer structure indeed can increase the channel value. But when we take a long-term view, is there any limitation to this structure?

Proposition 3. If the product lasts for three periods, adding two identical retailers would make the channel value the greatest when the manufacturer depends only on retailers to sell the durable goods.

Proof. See Appendix B.

Note the optimal number of retailers reduces to two in three periods. This phenomenon is not accidental. A longer product life cycle increases the severity of time inconsistency. Now the channel's commitment problem rather than underproduction becomes a major factor. Because the multipleretailer structure can only mitigate double marginalization and aggravate time inconsistency compared with the oneretailer decentralization, its flexibility is restricted. With the further increase of the product life cycle, it is plausible to believe the optimal number of retailers will finally reduce to one and the multiple-retailer structure degenerates to oneretailer decentralization. Given the weakness of the multipleretailer structure, one may wonder are there other ways that can eliminate both double marginalization and time inconsistency?

\section{Manufacturer Encroachment}

When the manufacturer encroaches on the retailer's operations by selling directly to customers through an e-channel, it also can mitigate double marginalization. Although common wisdom suggests a retailer suffers from its supplier's encroachment, Arya et al. [3] find this encroachment may be beneficial to the retailer and even the entire channel under some circumstances in a nondurable setting. Then, is the 
encroachment also a promising way to increase the channel value in a durable setting?

Next, we will take the most important scenario as an example to show how to compute the equilibrium. In addition, we only list the values of Lagrangian multipliers that will lead to the final subgame perfect equilibrium. Others will result in either invalid or suboptimal solutions and are not shown here.

In Period 2, because we consider only sequential encroachment, the manufacturer first chooses $q_{m}^{2}$ to maximize her Period 2 profit for given $q_{r}^{1}, q_{m}^{1}, q_{r}^{2}$, and $w_{m}^{2}$. The manufacturer's Period 2 problem now is

$$
\begin{aligned}
\max _{q_{m}^{2}} & V_{m}^{2} \\
& =\left[\alpha-\beta\left(q_{r}^{1}+q_{m}^{1}+q_{r}^{2}+q_{m}^{2}\right)-c\right] q_{m}^{2}+w_{m}^{2} q_{r}^{2}
\end{aligned}
$$

s.t. $\quad q_{m}^{2} \geq 0$.

The Lagrangian of the manufacturer's Period 2 profit is

$$
\begin{aligned}
L_{m}^{2}= & {\left[\alpha-\beta\left(q_{r}^{1}+q_{m}^{1}+q_{r}^{2}+q_{m}^{2}\right)-c\right] q_{m}^{2}+w_{m}^{2} q_{r}^{2} } \\
& +\lambda q_{m}^{2} .
\end{aligned}
$$

Solving (15) with $\lambda=0$, we obtain

$$
q_{m}^{2 *}=\frac{\alpha-\beta\left(q_{r}^{1}+q_{m}^{1}+q_{r}^{2}\right)-c}{2 \beta} .
$$

To ensure $q_{m}^{2 *} \geq 0$, all the other given parameters must satisfy $\alpha-c-\beta\left(q_{r}^{1}+q_{m}^{1}+q_{r}^{2}\right) \geq 0$.

Recognizing the response, the retailer chooses $q_{r}^{2}$ to maximize her Period 2 profit under a new constraint $\alpha-c-$ $\beta\left(q_{r}^{1}+q_{m}^{1}+q_{r}^{2}\right) \geq 0$ along with the original nonnegativity constraint $q_{r}^{2} \geq 0$. The retailer's Period 2 problem now is

$$
\begin{array}{ll}
\max _{q_{r}^{2}} & V_{r}^{2}=\left[\alpha-\beta\left(q_{r}^{1}+q_{m}^{1}+q_{r}^{2}+q_{m}^{2 *}\right)-w_{m}^{2}\right] q_{r}^{2} \\
\text { s.t. } & \alpha-c-\beta\left(q_{r}^{1}+q_{m}^{1}+q_{r}^{2}\right) \geq 0, \\
& q_{r}^{2} \geq 0 .
\end{array}
$$

The Lagrangian of the retailer's Period 2 profit is

$$
\begin{aligned}
L_{r}^{2}= & {\left[\alpha-\beta\left(q_{r}^{1}+q_{m}^{1}+q_{r}^{2}+q_{m}^{2 *}\right)-w_{m}^{2}\right] q_{r}^{2}+\lambda 1 q_{r}^{2} } \\
& +\lambda 2\left[\alpha-c-\beta\left(q_{r}^{1}+q_{m}^{1}+q_{r}^{2}\right)\right] .
\end{aligned}
$$

Solving the system with $\lambda 1=0$ and $\lambda 2=\left[\beta\left(q_{r}^{1}+q_{m}^{1}\right)-\right.$ $\left.2 w_{m}^{2}+3 c-\alpha\right] / 2 \beta$, we obtain

$$
q_{r}^{2 *}=\frac{\alpha-\beta\left(q_{r}^{1}+q_{m}^{1}\right)-c}{\beta} .
$$

To ensure $\lambda 2 \geq 0$ and $q_{r}^{2 *} \geq 0$, all the other given parameters should meet the requirements: $\beta\left(q_{r}^{1}+q_{m}^{1}\right)-2 w_{m}^{2}+$ $3 c-\alpha \geq 0$ and $\alpha-c-\beta\left(q_{r}^{1}+q_{m}^{1}\right) \geq 0$.
Note that the expression of $q_{r}^{2 *}$ does not include the wholesale price $w_{m}^{2}$ and the manufacturer's Period 2 profit is a linear increasing function of $w_{m}^{2}$. Recall that $w_{m}^{2}$ must satisfy the constraint $\beta\left(q_{r}^{1}+q_{m}^{1}\right)-2 w_{m}^{2}+3 c-\alpha \geq 0$; hence, its optimal value is

$$
w_{m}^{2 *}=\frac{3 c+\beta\left(q_{r}^{1}+q_{m}^{1}\right)-\alpha}{2} .
$$

Back to Period 1, both players make their decisions anticipating the optimal wholesale prices, production levels, and constraints in Period 2. Again the manufacturer first chooses the quantity selling through the e-channel to maximize her Period 1 profit under the constraint carried from Period 2 and the original nonnegativity constraint. The manufacturer's Period 1 problem now is

$$
\begin{aligned}
\max _{q_{m}^{1}} & V_{m}^{1} \\
= & {\left[2 \alpha-\beta\left(2 q_{r}^{1}+2 q_{m}^{1}+q_{r}^{2 *}+q_{m}^{2 *}\right)-c\right] q_{m}^{1} } \\
& +w_{m}^{1} q_{r}^{1}+V_{m}^{2 *}
\end{aligned}
$$

s.t. $\quad \alpha-c-\beta\left(q_{r}^{1}+q_{m}^{1}\right) \geq 0$,

$$
q_{m}^{1} \geq 0 \text {. }
$$

The Lagrangian of the manufacturer's Period 1 profit is

$$
\begin{aligned}
L_{m}^{1}= & {\left[2 \alpha-\beta\left(2 q_{r}^{1}+2 q_{m}^{1}+q_{r}^{2 *}+q_{m}^{2 *}\right)-c\right] q_{m}^{1} } \\
& +w_{m}^{1} q_{r}^{1}+V_{m}^{2 *}+\lambda 1 q_{m}^{1} \\
& +\lambda 2\left[\alpha-c-\beta\left(q_{r}^{1}+q_{m}^{1}\right)\right] .
\end{aligned}
$$

Solving the system with $\lambda 1=\lambda 2=0$, we obtain

$$
q_{m}^{1 *}=\frac{2\left(\alpha-\beta q_{r}^{1}-c\right)}{3 \beta} .
$$

To ensure $q_{m}^{1 *} \geq 0$, it requires $\alpha-\beta q_{r}^{1}-c \geq 0$.

Again foreseeing this response, the retailer chooses $q_{r}^{1}$ to maximize her Period 1 profit. The retailer's Period 1 problem now is

$$
\begin{aligned}
\max _{q_{r}^{1}} & V_{r}^{1} \\
= & {\left[2 \alpha-\beta\left(2 q_{r}^{1}+2 q_{m}^{1 *}+q_{r}^{2 *}+q_{m}^{2 *}\right)-w_{m}^{1}\right] q_{r}^{1} } \\
& +V_{r}^{2 *}
\end{aligned}
$$

s.t. $\quad \alpha-\beta q_{r}^{1}-c \geq 0$,

$$
q_{r}^{1} \geq 0
$$

The Lagrangian of the retailer's Period 1 profit is

$$
\begin{aligned}
L_{r}^{1}= & {\left[2 \alpha-\beta\left(2 q_{r}^{1}+2 q_{m}^{1 *}+q_{r}^{2 *}+q_{m}^{2 *}\right)-w_{m}^{1}\right] q_{r}^{1} } \\
& +V_{r}^{2 *}+\lambda 1 q_{r}^{1}+\lambda 2\left(\alpha-\beta q_{r}^{1}-c\right) .
\end{aligned}
$$


Solving the system with $\lambda 1=0$ and $\lambda 2=(7 c-\alpha-$ $\left.3 w_{m}^{1}\right) / 3 \beta$, we obtain

$$
q_{r}^{1 *}=\frac{\alpha-c}{\beta}
$$

To ensure $\lambda 2 \geq 0, w_{m}^{1}$ must satisfy $3 w_{m}^{1} \leq 7 c-\alpha$.

Note that the expression of $q_{r}^{1 *}$ also does not include the wholesale price $w_{m}^{1}$ and the manufacturer's Period 1 profit is a linear increasing function of $w_{m}^{1}$. From the constraint $3 w_{m}^{1} \leq$ $7 c-\alpha$, we obtain

$$
w_{m}^{1 *}=\frac{7 c-\alpha}{3}
$$

To ensure $w_{m}^{1 *} \geq 0, c$ must satisfy $7 c \geq \alpha$. We summarize the equilibrium wholesale prices, production levels, and channel value in this scenario as follows:

$$
\begin{aligned}
& w_{m}^{1 *}=\frac{7 c-\alpha}{3} ; \\
& w_{m}^{2 *}=c ; \\
& q_{r}^{1 *}=\frac{\alpha-c}{\beta} ; \\
& q_{r}^{2 *}=q_{m}^{1 *}=q_{m}^{2 *}=0 ; \\
& V^{*}=\frac{2 c(\alpha-c)}{\beta} .
\end{aligned}
$$

The above 6-stage backward induction with constrained optimization is tedious, but it has to be done like this. Otherwise, the subgame perfection of the equilibrium can not be guaranteed. Note that we only calculate one scenario. The whole set of scenarios and their boundaries are summarized below.

Proposition 4. If a durable goods manufacturer sells through an independent retailer in two periods and has the option to open a direct channel, there are five scenarios characterizing the equilibrium wholesale prices and production levels according to different values of the direct channel's unit cost c:

(A) If $0<c<\sigma_{1}$, then the manufacturer opens a direct channel in both periods and the retailer sells only in Period 1.

(B) If $\sigma_{1}<c<\sigma_{2}$, then the manufacturer opens a direct channel only in Period 1 and the retailer sells in both periods.

(C) If $\sigma_{2}<c<\sigma_{3}$, then the manufacturer does not open a direct channel in both periods and the retailer sells only in Period 1.

(D) If $\sigma_{3}<c<\sigma_{4}$, then the manufacturer opens a direct channel only in Period 1 and the retailer sells in both periods.

(E) If $\sigma_{4}<c<1$, then the manufacturer does not open a direct channel in both periods and the retailer sells in both periods.
Note. $\sigma_{1} \approx 0.32 \alpha, \sigma_{2} \approx 0.47 \alpha, \sigma_{3} \approx 0.80 \alpha$, and $\sigma_{4} \approx 0.99 \alpha$.

Proof. See Appendix A for the whole set of equilibriums.

Now we can turn our attention to how the manufacturer's encroachment will affect the interplay between double marginalization and time inconsistency. Note that the above scenario that we have analyzed in detail is actually Scenario (C) described in Proposition 4. Now the overall production in Period 1 is $q_{r}^{1 *}+q_{m}^{1 *}=(\alpha-c) / \beta$. If $c=\alpha / 2$, which lies in the boundary of Scenario $(\mathrm{C})$, the overall production in Period 1 is just the ideal value and the complaint of underproduction is completely eliminated. Then, we find the overall production in Period 2 is $q_{r}^{2 *}+q_{m}^{2 *}=0$, which is also the ideal production we desire, and the channel value $V^{*}=2 c(\alpha-c) / \beta=\alpha^{2} / 2 \beta$ reaches its maximum. Thus, both double marginalization and time inconsistency are eliminated and the whole channel is well coordinated.

Proposition 5. If the unit cost $c$ of opening a direct channel satisfies $c=\alpha / 2$ in the manufacturer encroachment structure, both double marginalization and time inconsistency are eliminated and the channel value reaches its maximum $V^{*}=\alpha^{2} / 2 \beta$.

When the unit cost of opening a direct channel reaches a certain value, the manufacturer has the option to open an e-channel but restrains from selling any product through it. Therefore, the e-channel is only a sham. Using a sham echannel has two effects. In Period 1, it can force the retailer to decrease the retail price and increase order quantity for the retailer now faces the potential threat of direct selling. Hence, the double marginalization is eliminated. Because the underproduction problem in Period 1 is solved, there are enough durable goods at the beginning of Period 2. This forces the retailer to quit from the market in Period 2 and time inconsistency is also eliminated. The sham e-channel strategy for the manufacturer has been discussed by many other papers. Chiang et al. [17] point out that "it is sometimes for an independent manufacturer to open a direct channel although no direct sales occur." Liu et al. [13] even show an incumbent conventional retailer can deter a pure etailer's online entry simply by refraining from entering online. In practice, there are also many firms like $3 \mathrm{M}$, NEC, and Whirlpool who use the Internet only as a medium for product information provision and accept no orders from it. Webb [18] reports the reason for them to do so is not to upset their resellers, while our results provide another explanation for this phenomenon.

Note that, in this ideal circumstance, the profits of the manufacturer and the retailer are $V_{m}^{*}=5 \alpha^{2} / 12 \beta$ and $V_{r}^{*}=\alpha^{2} / 12 \beta$, respectively. Although the manufacturer still could not achieve her optimal monopolistic profit, the whole channel is well coordinated. And most importantly, it does not require any commitment. Desai et al. [4] show a durable manufacturer can acquire her optimal monopolistic profit by writing a two-part contract with the retailer. But their model requires that the manufacturer can commit to wholesale prices. Sometimes, such commitment is difficult. 
Hence, if the whole channel could be coordinated without any commitment, the result is more universal.

Another interesting phenomenon occurs in Scenarios (B) and (C), where the channel suffers an overproduction problem and the customers' rational expectation has been reversed. First we write out the equilibrium wholesale prices and production levels in Scenario (B) as follows:

$$
\begin{aligned}
& w_{m}^{1 *}=\frac{19 \alpha+62 c}{63} ; \\
& w_{m}^{2 *}=\frac{59 c-8 \alpha}{42} ; \\
& q_{r}^{1 *}=\frac{10 c-\alpha}{7 \beta} ; \\
& q_{r}^{2 *}=\frac{8 \alpha-17 c}{21 \beta} ; \\
& q_{m}^{1 *}=\frac{2(8 \alpha-17 c)}{21 \beta} ; \\
& q_{m}^{2 *}=0
\end{aligned}
$$

Now the overall production in Period 1 is $q_{r}^{1 *}+q_{m}^{1 *}=$ $(13 \alpha-4 c) / 21 \beta$, which is always greater than $0.5 \alpha / \beta$ in the boundary of Scenario (B). $0.5 \alpha / \beta$ is the ideal production level in Period 1 or, in other words, the one-period optimal monopolistic leasing production level where customers do not have any rational expectation. This suggests customers' fear that the holding value of the goods they purchased in Period 1 will be reduced has been reversed and becomes the fear that if they postpone their purchases to Period 2, they may risk being charged at a relative higher price. In this sense, we say the customers' rational expectation has been reversed. This can be further explained as follows. Now the selling price discrepancy between the two periods is $2(2 \alpha+c) / 21$, which is always below the ideal discrepancy level $\alpha / 2$ in the boundary of Scenario (B). That means the holding value of goods purchased in Period 1 never reduces but increases in some sense. Hence, the channel seeks to encourage customers to purchase in Period 1 rather than waiting for reduced prices in Period 2. In the meanwhile, the manufacturer opens a direct channel and alleviates double marginalization in Period 1. This behavior acts in concert with the Period 2 encouragement. Foreseeing this, customers strive to purchase in Period 1. We summarize this phenomenon in Proposition 6.

Proposition 6. If the unit cost of opening a direct channel $c$ satisfies $\sigma_{1}<c<0.5 \alpha$, the customers' rational expectation would be reversed and there is an overproduction problem in Period 1 in the manufacturer encroachment structure.

Like underproduction, overproduction in Period 1 also makes the channel suffers. This can be testified by the fact that the channel value never reaches its maximum in the region $\sigma_{1}<c<0.5 \alpha$. It is easy to see the overproduction in Period 1 reaches its maximum at the point $c=\sigma_{1}$ and diminishes gradually as $c$ increases. This is because $\sigma_{1}$ is the

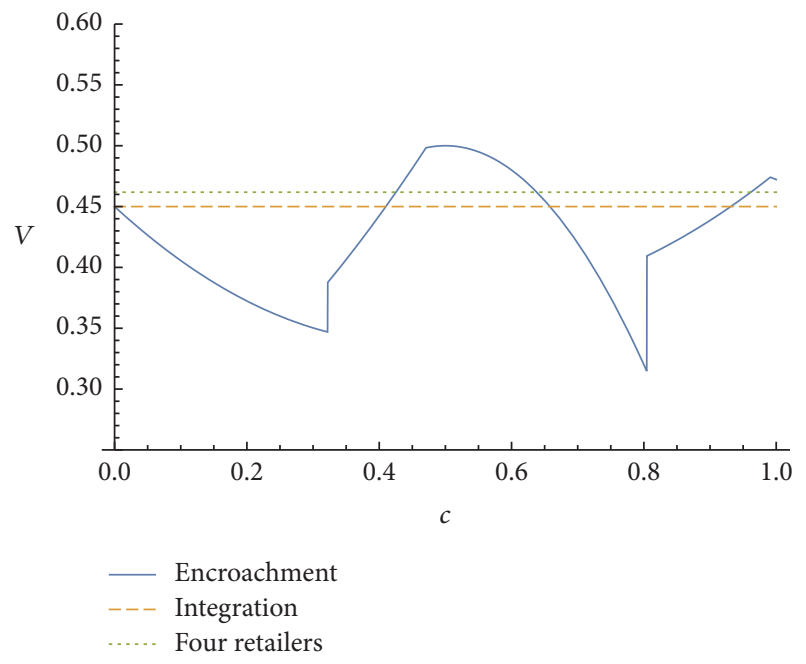

FIGURE 1: Profits of the whole channel under integration, four retailers, and encroachment.

point where the manufacturer closes the direct channel in Period 2 but still keeps it in Period 1. As $c$ increases, the manufacturer begins to decrease the quantity selling through the direct channel because of the increasing operating cost. This tendency curbs customers' purchasing desire and the overproduction in Period 1 also diminishes. Although overall production in Period 1 raises again at the point $c=\sigma_{3}$, the operating cost of the direct channel is so huge that it never favors another overproduction. Overproduction also never occurs in Scenario (A), whose boundary is $0<c<\sigma_{1}$. This is because then the selling price discrepancy between the two periods is always above the ideal discrepancy level $\alpha / 2$.

Although, in some circumstances, the manufacturer encroachment structure proves to be a perfect coordination mechanism for the entire channel, it is not a panacea. Specifically, the benefit it brings is at the mercy of its unit operating cost. The cost factor can not be neglected. For example, in Scenario (A), the overall production in Period 1 is $2(9 \alpha+5 c) / 45 \beta$, which is always greater than that under integration. This implies the underproduction problem is alleviated to some extent. In Period 2, the overall production is $(27 \alpha-55 c) / 90 \beta$, which is always less than that under integration, suggesting the commitment problem is also mitigated. But the channel value in Scenario (A) never exceeds that under integration because the benefit is outweighed by the cost resulting from operating the direct channel. On the other hand, the multiple-retailer structure is more robust and is not likely to be criticized for excessive exploit of the manufacturer's loyal retailer. Therefore, we compare the two structures (according to Proposition 2, we choose four retailers in the multiple-retailer structure) in the sense of the whole channel value and depict them in Figure 1 where both $\alpha$ and $\beta$ are set to 1 .

\section{Conclusion}

Multiple-retailer and manufacturer encroachment are two prevalent patterns adopted by manufacturers in the sale of 
durable goods. In this paper, we study the two patterns and investigate their impacts to the profit of the whole supply chain in a durable goods setting.

Our analysis generates two new managerial insights. First and the most important is that we show the competition between retailers is sufficient to make the profit of a durable goods channel exceed that under integration in just two periods. Arya and Mittendorf [5] find that under some circumstances the channel discord brought about by an intermediary can make a decentralized channel more appealing than an integrated one in a durable goods setting. But in their model, to achieve that goal, a longer product life cycle has to be investigated (at least three periods), while we demonstrate this can be achieved in just two periods.

Another important insight is that we demonstrate manufacturer encroachment can be an effective means of coordinating the durable goods supply chain. Numerous contracts have been proposed to solve the coordination problem and it is not an easy task to coordinate a dual channel when goods are nondurable. The contract must go beyond eliminating double marginalization in a single-channel supply chain and account for interdistribution competition between the two channels, while our results show there is no need to devise sophisticated contracts under some circumstances. Moreover, this method does not require any commitment. Desai et al. [4] show a durable manufacturer can acquire her optimal monopolistic profit by writing a two-part contract with the retailer. But their model requires that the manufacturer can commit to prices they will charge the retailer. Sometimes, making such commitment is difficult. In addition, if the manufacturer has an ability to make such commitment, she may also be able to commit to prices with customers. In that case, the time inconsistency problem would not exist in the first place. Therefore, if the whole channel could be coordinated without any commitment, the result will be more convincing and universal.

\section{Appendix}

\section{A. The Whole Set of Equilibriums in Proposition 4}

The other scenarios can be calculated following the same steps described in Section 6 and are not shown here. Comparing the manufacturer's profits in each scenario defines all the boundaries. We summarize the equilibrium wholesale prices, production levels, and channel value in each scenario as follows:

(A) The boundary is $0<c<\sigma_{1}$; the optimal decisions of both players are

$$
\begin{aligned}
& w_{m}^{1 *}=\frac{27 \alpha-5 c}{30} \\
& w_{m}^{2 *}=\frac{27 \alpha+35 c}{90} \\
& q_{r}^{1 *}=\frac{10 c}{27 \beta}
\end{aligned}
$$

$$
\begin{aligned}
q_{r}^{2 *} & =0 ; \\
q_{m}^{1 *} & =\frac{2(27 \alpha-10 c)}{135 \beta} ; \\
q_{m}^{2 *} & =\frac{27 \alpha-55 c}{90 \beta} ; \\
V^{*} & =\frac{729 \alpha^{2}-810 \alpha c+905 c^{2}}{1620 \beta} .
\end{aligned}
$$

(B) The boundary is $\sigma_{1}<c<\sigma_{2}$; the optimal decisions of both players are

$$
\begin{aligned}
& w_{m}^{1 *}=\frac{19 \alpha+62 c}{63} ; \\
& w_{m}^{2 *}=\frac{59 c-8 \alpha}{42} ; \\
& q_{r}^{1 *}=\frac{10 c-\alpha}{7 \beta} ; \\
& q_{r}^{2 *}=\frac{8 \alpha-17 c}{21 \beta} ; \\
& q_{m}^{1 *}=\frac{2(8 \alpha-17 c)}{21 \beta} ; \\
& q_{m}^{2 *}=0 ; \\
& V^{*}=\frac{104 \alpha^{2}+125 \alpha c+257 c^{2}}{441 \beta} .
\end{aligned}
$$

(C) The boundary is $\sigma_{2}<c<\sigma_{3}$; the optimal decisions of both players are

$$
\begin{aligned}
& w_{m}^{1 *}=\frac{7 c-\alpha}{3} ; \\
& w_{m}^{2 *}=c ; \\
& q_{r}^{1 *}=\frac{\alpha-c}{\beta} ; \\
& q_{r}^{2 *}=q_{m}^{1 *}=q_{m}^{2 *}=0 ; \\
& V^{*}=\frac{2 c(\alpha-c)}{\beta} .
\end{aligned}
$$

(D) The boundary is $\sigma_{3}<c<\sigma_{4}$; the optimal decisions of both players are

$w_{m}^{1 *}=\frac{95599 \alpha}{102752}-\frac{3581 c}{25688} ;$

$w_{m}^{2 *}=\frac{539 \alpha}{1976}+\frac{201 c}{3458}$

$q_{r}^{1 *}=\frac{1324 c-49 \alpha}{3724 \beta} ;$ 


$$
\begin{aligned}
q_{r}^{2 *} & =\frac{3773 \alpha+804 c}{27664 \beta} ; \\
q_{m}^{1 *} & =\frac{11319 \alpha-11420 c}{24206 \beta} ; \\
q_{m}^{2 *} & =0 \\
V^{*} & \\
& =\frac{374745679 \alpha^{2}-353843112 \alpha c+344894320 c^{2}}{765296896 \beta} .
\end{aligned}
$$

(E) The boundary is $\sigma_{4}<c<1$; the optimal decisions of both players are

$$
\begin{aligned}
& w_{m}^{1 *}=\frac{91 c-49 \alpha}{52} ; \\
& w_{m}^{2 *}=\frac{c}{3} \\
& q_{r}^{1 *}=\frac{3 \alpha-2 c}{3 \beta} ; \\
& q_{r}^{2 *}=\frac{c}{6 \beta} ; \\
& q_{m}^{1 *}=q_{m}^{2 *}=0 \\
& V^{*}=\frac{c(42 \alpha-25 c)}{36 \beta}
\end{aligned}
$$

where $\sigma_{1} \approx 0.32 \alpha, \sigma_{2} \approx 0.47 \alpha, \sigma_{3} \approx 0.80 \alpha$, and $\sigma_{4} \approx 0.99 \alpha$.

\section{B. Proofs}

Proof of Proposition 2. Suppose there are $n$ identical retailers competing in the market. We first examine Retailer 1's Period 2 problem:

$$
\begin{aligned}
\max _{q_{r 1}^{2}} & V_{r 1}^{2} \\
& =\left[\alpha-\beta\left(q_{r 1}^{1}+\cdots+q_{r n}^{1}+q_{r 1}^{2}+\cdots+q_{r n}^{2}\right)-w_{m}^{2}\right] q_{r 1}^{2} .
\end{aligned}
$$

Taking Retailer 1's first-order condition and making use of symmetry, we obtain the $n$ identical retailers' optimal responses in Period 2:

$$
\begin{aligned}
q_{r 1}^{2 *} & =q_{r 2}^{2 *}=\cdots=q_{r n}^{2 *} \\
& =\frac{\alpha-\beta\left(q_{r 1}^{1}+\cdots+q_{r n}^{1}\right)-w_{m}^{2}}{(n+1) \beta} .
\end{aligned}
$$

Recognizing those responses, the manufacturer chooses the second-period wholesale price $w_{m}^{2}$ to maximize her Period 2 profit. The manufacturer's Period 2 problem is

$$
\max _{w_{m}^{2}} V_{m}^{2}=w_{m}^{2}\left(q_{r 1}^{2 *}+\cdots+q_{r n}^{2 *}\right) .
$$
price:

Taking first-order condition yields Period 2 wholesale

$$
w_{m}^{2 *}=\frac{\alpha-\beta\left(q_{r 1}^{1}+\cdots+q_{r n}^{1}\right)}{2} .
$$

Back to Period 1, the identical retailers again make their decisions simultaneously. Now Retailer 1's Period 1 problem is

$$
\max _{q_{r 1}^{1}} \quad V_{r 1}^{1}=\left[2 \alpha-\beta\left(2 q_{r 1}^{1}+\cdots+2 q_{r n}^{1}+q_{r 1}^{2 *}+\cdots+q_{r n}^{2 *}\right)-w_{m}^{1}\right] q_{r 1}^{1}+V_{r 1}^{2 *}
$$

Again, we make use of first-order condition and symmetry to obtain the $n$ identical retailers' optimal responses in Period 1:

$$
\begin{aligned}
q_{r 1}^{1 *} & =q_{r 2}^{1 *}=\cdots=q_{r n}^{1 *} \\
& =\frac{\left(3 n^{2}+7 n+3\right) \alpha-2(n+1)^{2} w_{m}^{1}}{(n+2)\left(3 n^{2}+4 n+2\right) \beta} .
\end{aligned}
$$

Recognizing those responses, the manufacturer chooses the first-period wholesale price $w_{m}^{1}$ to maximize her Period 1 profit. The manufacturer's Period 1 problem is

$$
\max _{w_{m}^{1}} V_{m}^{1}=w_{m}^{1}\left(q_{r 1}^{1 *}+\cdots+q_{r n}^{1 *}\right)+V_{m}^{2 *} .
$$

Again, taking first-order condition yields Period 1 wholesale price. We summarize the equilibrium wholesale prices, order quantities, and channel value as follows:

$$
\begin{aligned}
& w_{m}^{1 *}=\frac{\left(9 n^{5}+54 n^{4}+119 n^{3}+123 n^{2}+62 n+12\right) \alpha}{2(n+1)^{2}\left(5 n^{3}+19 n^{2}+20 n+8\right)} \\
& w_{m}^{2 *}=\frac{\left(3 n^{3}+13 n^{2}+17 n+8\right) \alpha}{2\left(5 n^{3}+19 n^{2}+20 n+8\right)}
\end{aligned}
$$




$$
\begin{aligned}
& q_{r 1}^{1 *}=q_{r 2}^{1 *}=\cdots=q_{r n}^{1 *}=\frac{\left(2 n^{2}+6 n+3\right) \alpha}{\left(5 n^{3}+19 n^{2}+20 n+8\right) \beta} ; \\
& q_{r 1}^{2 *}=q_{r 2}^{2 *}=\cdots=q_{r n}^{2 *}=\frac{\left(3 n^{3}+13 n^{2}+17 n+8\right) \alpha}{2(n+1)\left(5 n^{3}+19 n^{2}+20 n+8\right) \beta} ; \\
& V^{*}=\frac{\left(15 n^{4}+83 n^{3}+161 n^{2}+132 n+40\right)\left(3 n^{3}+13 n^{2}+17 n+8\right) n \alpha^{2}}{4(n+1)^{2}\left(5 n^{3}+19 n^{2}+20 n+8\right)^{2} \beta} .
\end{aligned}
$$

Using numerical method, we find the optimal $n$ is $n^{*}=$ 4 and the corresponding optimal channel value is $V^{*} \approx$ $0.4618 \alpha^{2} / \beta$.

Proof of Proposition 3. There is no need to follow the same backward induction process as before which requires cycling through three periods. We will adopt the method described in [5] and replace the original demand intercept $\alpha$ with $\alpha-$ $\beta\left(q_{r 1}^{0}+\cdots+q_{r n}^{0}\right)$. Now the equilibrium wholesale prices and order quantities in Period s 1 and 2 become

$$
\begin{aligned}
& w_{m}^{1 *}=\frac{\left(9 n^{5}+54 n^{4}+119 n^{3}+123 n^{2}+62 n+12\right)\left(\alpha-\beta\left(q_{r 1}^{0}+\cdots+q_{r n}^{0}\right)\right)}{2(n+1)^{2}\left(5 n^{3}+19 n^{2}+20 n+8\right)} ; \\
& w_{m}^{2 *}=\frac{\left(3 n^{3}+13 n^{2}+17 n+8\right)\left(\alpha-\beta\left(q_{r 1}^{0}+\cdots+q_{r n}^{0}\right)\right)}{2\left(5 n^{3}+19 n^{2}+20 n+8\right)} ; \\
& q_{r 1}^{1 *}=q_{r 2}^{1 *}=\cdots=q_{r n}^{1 *}=\frac{\left(2 n^{2}+6 n+3\right)\left(\alpha-\beta\left(q_{r 1}^{0}+\cdots+q_{r n}^{0}\right)\right)}{\left(5 n^{3}+19 n^{2}+20 n+8\right) \beta} ; \\
& q_{r 1}^{2 *}=q_{r 2}^{2 *}=\cdots=q_{r n}^{2 *}=\frac{\left(3 n^{3}+13 n^{2}+17 n+8\right)\left(\alpha-\beta\left(q_{r 1}^{0}+\cdots+q_{r n}^{0}\right)\right)}{2(n+1)\left(5 n^{3}+19 n^{2}+20 n+8\right) \beta} .
\end{aligned}
$$

And Period 0 inverse demand function is

$$
\begin{aligned}
p_{s}^{0} & =3 \alpha-\beta\left(3 q_{r 1}^{0}+\cdots+3 q_{r n}^{0}+2 q_{r 1}^{1}+\cdots+2 q_{r n}^{1}\right. \\
& \left.+q_{r 1}^{2}+\cdots+q_{r n}^{2}\right) .
\end{aligned}
$$

In Period 0 , the $n$ identical retailers again make their decisions simultaneously. Retailer 1's Period 0 problem is

$$
\max _{q_{r 1}^{0}} \quad V_{r 1}^{0}=\left[3 \alpha-\beta\left(3 q_{r 1}^{0}+\cdots+3 q_{r n}^{0}+2 q_{r 1}^{1 *}+\cdots+2 q_{r n}^{1 *}+q_{r 1}^{2 *}+\cdots+q_{r n}^{2 *}\right)-w_{m}^{0}\right] q_{r 1}^{0}+V_{r 1}^{1 *}
$$

Again, taking first-order condition and making use of symmetry, we obtain the identical retailers' optimal responses in Period 0:

$$
q_{r 1}^{0 *}=q_{r 2}^{0 *}=\cdots=q_{r n}^{0 *}=\frac{n_{1} \alpha-n_{2} w_{m}^{0}}{n_{3} \beta},
$$

where

$$
\begin{aligned}
n_{1}= & 95 n^{8}+951 n^{7}+3989 n^{6}+9187 n^{5}+12760 n^{4} \\
& +10972 n^{3}+5711 n^{2}+1644 n+200, \\
n_{2}= & 2(n+1)^{2}\left(5 n^{3}+19 n^{2}+20 n+8\right)^{2},
\end{aligned}
$$

$$
\begin{aligned}
n_{3}= & 95 n^{9}+1046 n^{8}+4940 n^{7}+13209 n^{6}+22237 n^{5} \\
& +24747 n^{4}+18495 n^{3}+9108 n^{2}+2728 n \\
& +384
\end{aligned}
$$

Recognizing those responses, the manufacturer chooses Period 0 wholesale price $w_{m}^{0}$ to maximize her Period 0 profit. The manufacturer's Period 0 problem is

$$
\max _{w_{m}^{0}} V_{m}^{0}=w_{m}^{0}\left(q_{r 1}^{0 *}+\cdots+q_{r n}^{0 *}\right)+V_{m}^{1 *} .
$$


Taking first-order condition yields Period 0 wholesale price. Substituting all the optimal decisions back into Period 0 profits of the manufacturer and $n$ retailers and adding them up provide the channel value in three periods:

$$
V^{*}=\frac{n_{4} n_{5} \alpha^{2} n}{2 n_{2} n_{6} \beta},
$$

where

$$
\begin{aligned}
n_{4} & =95 n^{9}+1141 n^{8}+5891 n^{7}+17231 n^{6}+31714 n^{5} \\
& +38522 n^{4}+31279 n^{3}+16572 n^{2}+5256 n+768 \\
n_{5} & =13775 n^{16}+291225 n^{15}+2841374 n^{14} \\
& +16994860 n^{13}+69814778 n^{12}+209116606 n^{11} \\
& +473108544 n^{10}+826044601 n^{9} \\
& +1126927053 n^{8}+1207638262 n^{7} \\
& +1015287309 n^{6}+664064512 n^{5}+332011824 n^{4} \\
& +122950592 n^{3}+31881152 n^{2}+5184512 n \\
& +399360 \\
n_{6} & =\left(768+5456 n+18080 n^{2}+36138 n^{3}\right. \\
& +47195 n^{4}+41049 n^{5}+23413 n^{6}+8353 n^{7} \\
& \left.+1681 n^{8}+145 n^{9}\right)^{2} .
\end{aligned}
$$

Using numerical method, we find the optimal $n$ is $n^{*}=$ 2 and the corresponding optimal channel value is $V^{*} \approx$ $0.6646 \alpha^{2} / \beta$.

\section{Competing Interests}

The authors declare that there is no conflict of interests regarding the publication of this paper.

\section{Acknowledgments}

This research is supported by the National Natural Science Foundation of China under Grant nos. 71271225 and 71301178 and by Chongqing Graduate Student Innovation Research Project (CYB14001).

\section{References}

[1] W. S. Yoo and E. Lee, "Internet channel entry: a strategic analysis of mixed channel structures," Marketing Science, vol. 30, no. 1, pp. 29-41, 2011.

[2] D. Zehr, "Dell to close all us kiosks as it moves pcs into stores," Austin American Statesman, 2008.

[3] A. Arya, B. Mittendorf, and D. E. M. Sappington, "The bright side of supplier encroachment," Marketing Science, vol. 26, no. 5, pp. 651-659, 2007.
[4] P. Desai, O. Koenigsberg, and D. Purohit, "Strategic decentralization and channel coordination," Quantitative Marketing \& Economics, vol. 2, no. 1, pp. 5-22, 2004.

[5] A. Arya and B. Mittendorf, "Benefits of channel discord in the sale of durable goods," Marketing Science, vol. 25, no. 1, pp. 9196, 2006.

[6] D. Purohit, "Marketing channels and the durable goods monopolist: renting versus selling reconsidered," Journal of Economics \& Management Strategy, vol. 4, no. 1, pp. 69-84, 1995.

[7] R. H. Coase, "Durability and monopoly," The Journal of Law and Economics, vol. 15, no. 1, pp. 143-149, 1972.

[8] D. Fudenberg and J. Tirole, "Upgrades, tradeins, and buybacks," The RAND Journal of Economics, vol. 29, no. 2, pp. 235-258, 1997.

[9] S. Huang, Y. Yang, and K. Anderson, "A theory of finitely durable goods monopoly with used-goods market and transaction costs," Management Science, vol. 47, no. 11, pp. 1515-1532, 2001.

[10] K. Saggi and N. Vettas, "Leasing versus selling and firm efficiency in oligopoly," Economics Letters, vol. 66, no. 3, pp. 361$368,2000$.

[11] S. R. Bhaskaran and S. M. Gilbert, "Implications of channel structure for leasing or selling durable goods," Marketing Science, vol. 28, no. 5, pp. 918-934, 2009.

[12] G. Cai, "Channel selection and coordination in dual-channel supply chains," Journal of Retailing, vol. 86, no. 1, pp. 22-36, 2010.

[13] Y. Liu, S. Gupta, and Z. J. Zhang, "Note on self-restraint as an online entry-deterrence strategy," Management Science, vol. 52, no. 11, pp. 1799-1809, 2006.

[14] A. Arya, B. Mittendorf, and D.-H. Yoon, "Friction in relatedparty trade when a rival is also a customer," Management Science, vol. 54, no. 11, pp. 1850-1860, 2008.

[15] Y. Xiong, W. Yan, K. Fernandes, Z.-K. Xiong, and N. Guo, "Bricks vs. clicks': the impact of manufacturer encroachment with a dealer leasing and selling of durable goods," European Journal of Operational Research, vol. 217, no. 1, pp. 75-83, 2012.

[16] J. I. Bulow, "Durable-goods monopolists," Journal of Political Economy, vol. 90, no. 2, pp. 314-332, 1982.

[17] W.-Y. K. Chiang, D. Chhajed, and J. D. Hess, "Direct marketing, indirect profits: a strategic analysis of dual-channel supplychain design," Management Science, vol. 49, no. 1, pp. 1-20, 2003.

[18] K. L. Webb, "Managing channels of distribution in the age of electronic commerce," Industrial Marketing Management, vol. 31, no. 2, pp. 95-102, 2002. 


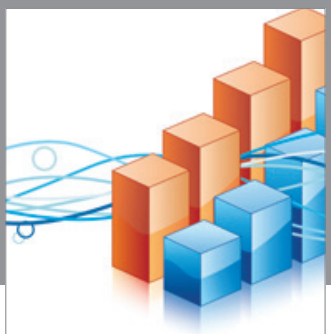

Advances in

Operations Research

vatem alat4

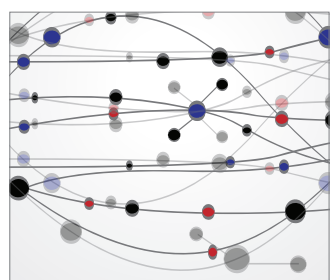

\section{The Scientific} World Journal
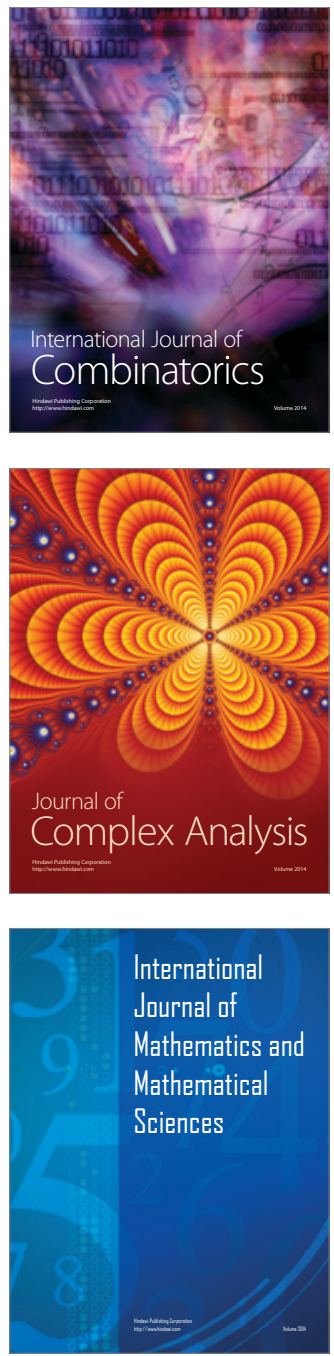
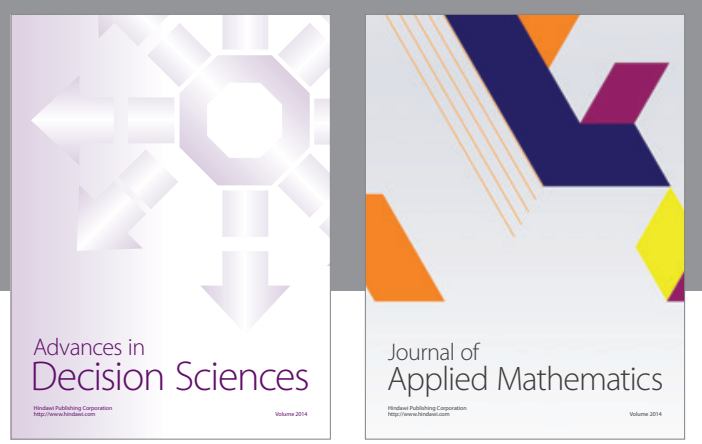

Algebra

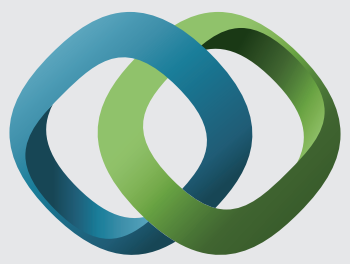

\section{Hindawi}

Submit your manuscripts at

http://www.hindawi.com
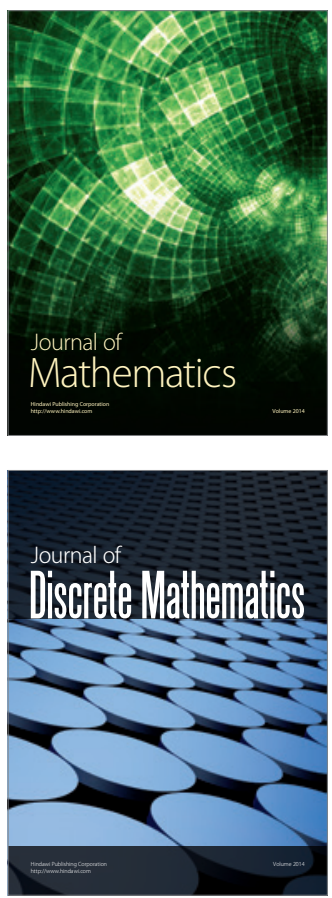

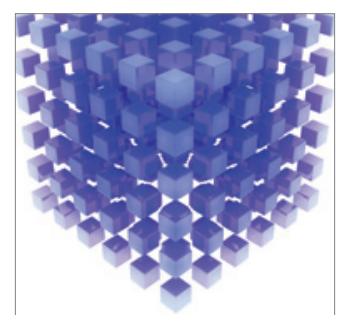

Mathematical Problems in Engineering
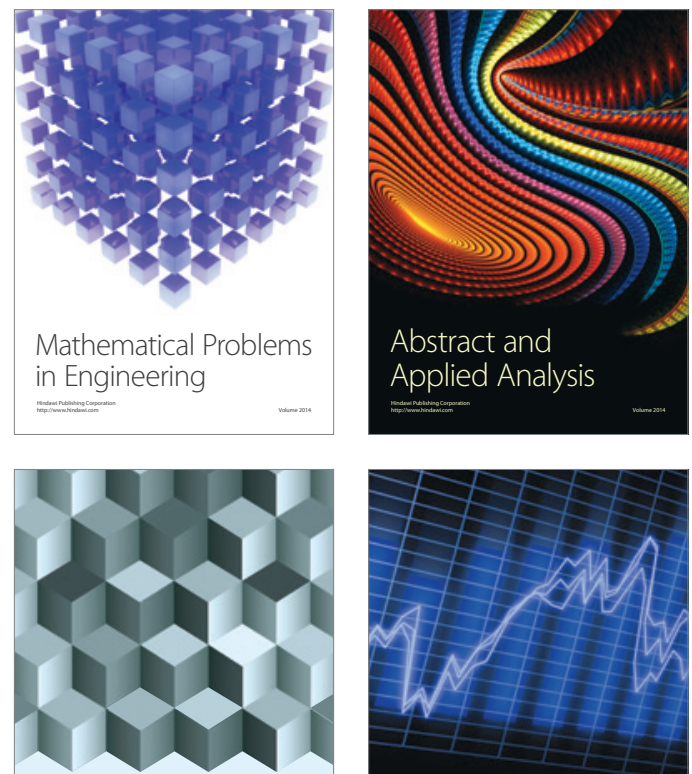

Journal of

Function Spaces

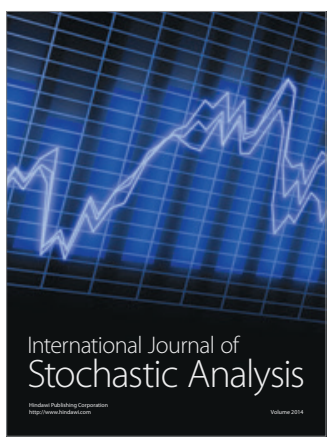

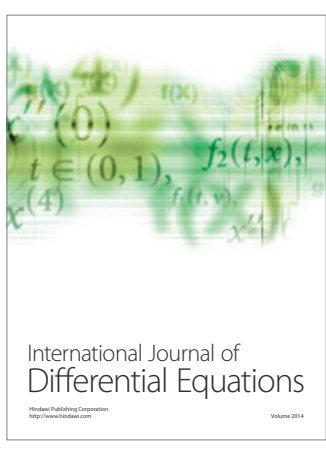
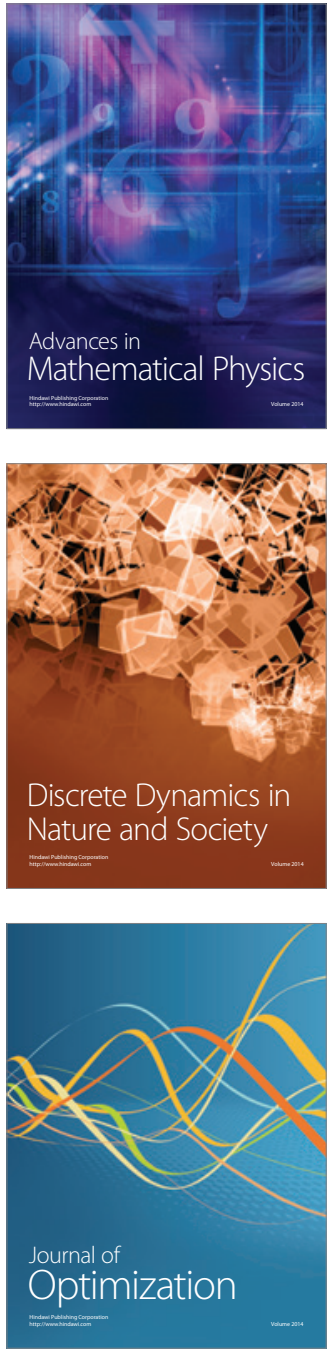